\title{
A practicable approach to providing horses in a standing position for teaching gross anatomy and surgery
}

\author{
Johanna Plendl', Kenneth C. Richardson², Kathrin Dietze ${ }^{3}$, Janet Weigner ${ }^{7}$ and Hana Hünigen ${ }^{\text {' }}$ \\ 1 Department of Veterinary Medicine, Institute for Veterinary Anatomy, Freie Universität Berlin, Germany \\ 2 College of Veterinary Medicine, Murdoch University, Murdoch, WA, Australia \\ ${ }^{3}$ Federal Office of Consumer Protection and Food Safety, Berlin, Germany
}

\begin{abstract}
Summary: Lifelike simulation of surgical procedures as well as whole body dissections of horses in a natural standing position are superior as they show the normal topographic visceral interrelationships between organs, their ligamentous associations, vasculature and innervation. This short technical communication reports on the fixation of small-frame horses in a standing position on a mobile frame. Animals are euthanased using standard veterinary protocols and heparinised to facilitate exsanguination. All steps including the embalming procedures/ protocols, the support of the body with fabric body harnesses, and additional means to place and hold the body in an as natural position as possible are described in detail. Following these procedures, animals were dissected over a time period of three-months and exposed tissue surfaces were swabbed weekly to determine their ongoing microbial status. No adverse effects, such as aerobic and anaerobic bacteria, yeast, or mould growth were found.
\end{abstract}

Keywords: horses, standing position, fixation, teaching, gross anatomy, surgery

Citation: Plendl J., Richardson K. C., Dietze K., Weigner J., Hünigen H. (2019) A practicable approach to providing horses in a standing position for teaching gross anatomy and surgery. Pferdeheilkunde 35, 537-540; DOI 10.21836/PEM20190606

Correspondence: Prof. Dr. med. vet. Johanna Plendl, Head of Institute, Institute for Veterinary Anatomy, Department of Veterinary Medicine, Freie Universitäł Berlin, Germany, Koserstraße 20, 14195 Berlin, Germany; johanna.plendl@fu-berlin.de

Received: July 22, 2019 | Accepted: October 4, 2019

\section{Introduction}

Horse practitioners often have to perform surgery, such as castration or minimally invasive laparoscopy, on standing sedated horses. When conducted in the standing position, the need for general anaesthesia and its associated risks can be avoided (Hendrickson 2012). However, students are only rarely given the opportunity to practise on cadavers of standing horses.

Due to the large size of horses, students often have little exposure to the basic anatomy of this species since many veterinary training institutions do not have the means to perform whole body dissections on standing horse cadavers either in their anatomy curriculum or in surgical simulation training in their clinical curriculum. Instead, such institutions focus on specific regions of significance such as the distal limb, or on organ systems such as the digestive system, for which representative abattoir specimens are suitable and usually readily available (Cake 2006).

Whole body dissection of horses is uncommon mostly due to physical constraints such as premises not being designed to allow large animals to be fixed, adequately stored and dissected. In addition, animal welfare issues imposed upon most universities limit the teaching, especially of large domestic species (Theoret et al. 2007, Tiplady et al. 2011).

Although more recently simulation models for surgical training in standing horses, e.g. a simulator for laparoscopic ovariectomy, have been designed, these models are not available commercially (Elarbi et al. 2018).

However, some institutions, such as the Freie Universität Berlin, have reached a compromised but educationally successful alternative that allows whole body dissection of large domestic species (Janczyk et al. 2011 a, Janczyk et al. 2011 b, Klopfleisch et al. 2013). At the Department of Veterinary Medicine of the Freie Universität Berlin, small-frame horses are acquired via a body donation program, euthanased, and subsequently placed in a standing position on a mobile frame. Once the limbs and head are positioned in an as natural position as possible, the animal is fixed 'in situ'. The initial selection of small-frame horses is essential.

\section{Animals and methods}

All procedures are undertaken using standard, ethically approved techniques and drug regimens. Animals having a 
disease with a poor prognosis are donated by their owners for the purpose of veterinary education. The animals used as the basis for this report were euthanased by a veterinarian in accordance with all relevant local animal welfare laws, guidelines, and policies (Landesamt für Gesundheit und Soziales Berlin, L 0089/14, 2014-2017).

After insertion of an intravenous catheter, animals are heparinised to facilitate exsanguination. Euthanasia is carried out using standard veterinary protocols.

Death is confirmed by cardiac arrest. Once euthanasia is complete, a $7 \mathrm{~cm}$ incision is made midway along the neck, parallel to and 2-3 cm dorsal to the jugular furrow. After localizing the carotid sheath, the common carotid artery together with its accompanying vagosympathetic trunk is dissected free from adjacent tissues and structures. Then the common carotid artery is freed from its attachment to the vagosympathetic trunk and elevated. Two loose ligatures are placed around the common carotid artery, the first close to site of the arterial catheterization incision and the second several centimetres distally. A $5 \mathrm{~mm}$ longitudinal incision is made in the common carotid artery and a cannula (diameter $9 \mathrm{~mm}$, length $90 \mathrm{~mm}$ ) is introduced with its blunt end directed towards the heart. The other end of the cannula is connected to a rubber tube (internal diameter $8 \mathrm{~mm}$, length $20 \mathrm{~cm}$ ) to allow arterial drainage. The common carotid artery is tied off towards the head, close to the incision site. Subsequently, the preplaced ligatures are tied off around the cannula and blood is allowed to drain from the body. If necessary, the whole body is elevated with the head and neck lowermost to allow gravity to assist exsanguination.

Subsequently, the carcass is cleaned and visible surface contaminants are removed from the coat of the animal.

Next, a broad fabric body harness is placed midway around the abdomen of the animal. Once the harness is in place, the animal is lifted by a hoist/crane into an upright posture and placed within a wheeled support-frame positioned below and around it (Fig. 1). Then a strong metal rod is passed through the insertion site of the nuchal ligament with $10 \mathrm{~cm}$ protruding from each side. A second rod is inserted below the tail base at the level of the proximal caudal vertebrae and also left in place with $10 \mathrm{~cm}$ protruding on each side. A rope is tied to one side of each transverse rod and then passed over the longitudinally oriented overhead rail of the support-frame and tied off to the other side of its respective transverse rod (Fig. 1). The animal is then positioned in a standing position in as natural a posture as possible. Once this is achieved each hoof is placed on the hardwood base of the frame and screwed in place (Fig. 1). To ensure the animal is fixed in a natural position, broad cloths are placed around the principal limb joints and adjusted and tied off to the nearby frame to attain a natural conformation of the limbs. The head is positioned using a broad cloth around the muzzle, which is tied off on the overhead rail.

Once the animal is in the required position, the carotid cannula is connected to a peristaltic pump outlet by flexible tubing (Thalheimer, Ellwangen, Germany). An appropriate fixative is perfused at a pressure of up to 2 bar for approximately
10-20 min. Fixation is complete once the animal is noticeably firm to touch and the muscles and joints have become stiff. After fixation, the abdominal body harness is removed and the animal is placed in a cooling chamber, where it is cooled to $4{ }^{\circ} \mathrm{C}$. After two to three days the stabilizing cloths are removed from the limbs and head. The support ropes to the neck and base of the tail are retained to stabilize the animal.

Finally, the coat of the animal is clipped short to remove surface contaminants and limit any future microbial growth. After that, the entire body is thoroughly scrubbed clean using liqvid detergents and disinfectants. Particular care is taken with cleaning the body orifices and the distal extremities.

Prior to dissection of the forelimbs, additional stabilizing wires are passed through two spinous processes of the withers and connected to the overhead rail of the support-frame.

Animals can be dissected progressively over 3-6 months with no negative effects on the quality of the specimens. At the end of each dissection class, animals are washed with a formaldehyde free solution $\left(\mathrm{H}_{2} \mathrm{O}[50 \%]\right.$, ethanol [30\%], glycol [20\%]).

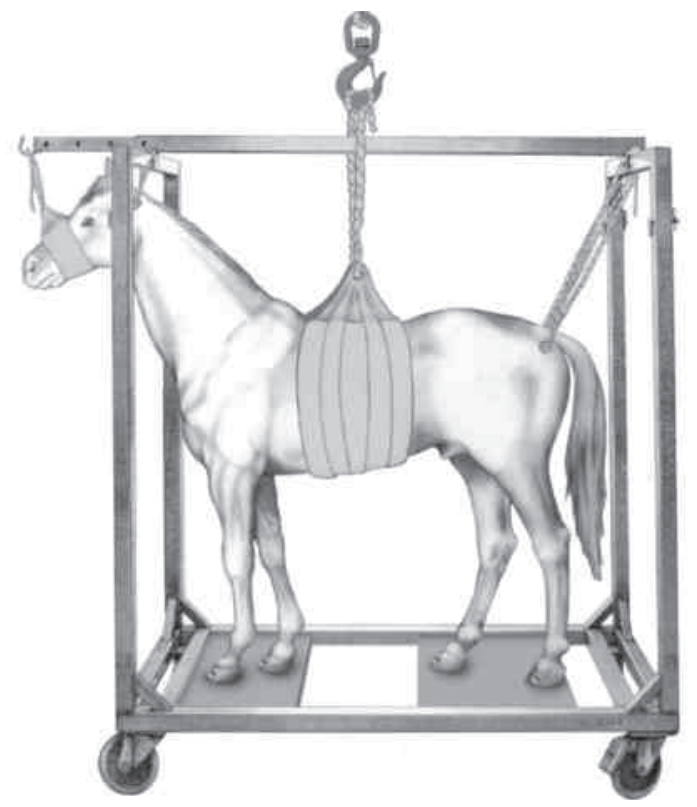

Fig. 1 A small horse in its mobile frame immediately following fixation in a natural standing position. It is still held upright by the hoist connected to a large cloth supporting the abdomen. Anteriorly, the head is supported by a broad cloth and posteriorly it is supported by a short rope running from the frame to a metal rod inserted transversely through the nuchal ligament insertion. The pelvic region is held up by a rope running from the frame to a metal rod passing transversely through the tail base in the region of the caudal vertebrae. Hooves of the animal are screwed onto the hardwood base of the frame. Cloths around the joints have been removed. | Kleinpferd in mobilem Metallrahmen in stehender Position. Das Präparat wird durch eine Hängematte um den Bauch aufrecht gehalten, die am Rahmen befestigt ist. Der Kopf wird sowohl durch ein breites Tuch als auch durch ein kurzes Seil gehalten, das vom Rahmen zu einem Metallstab verläuft, der transversal durch das Ligamentum nuchae hindurchgeführt wurde. Die Beckenregion wird durch ein Seil gehalten, das vom Rahmen zu einem Metallstab verläuft, der transversal durch die Schwanzwurzel in der Region der ersten Schwanzwirbel hindurchgeführt wurde. Die Hufe des Tieres werden auf der Platte, die die Basis des Rahmens bildet, festgeschraubt. (Die Tücher zur Stabilisierung der Gelenke sind auf der Zeichnung nicht dargestellt.) 
(Formaldehyde is classified as a "category 1B carcinogenic substance". Whilst the use of formaldehyde is permitted, since January 2016 compliance with a maximum workplace concentration (MAK) of $0.37 \mathrm{mg} / \mathrm{m}^{3}$ resp. $0.3 \mathrm{ml} / \mathrm{m}^{3}(0.3 \mathrm{ppm})$ has been legally mandatory). Subsequently, the animals are covered with damp cotton cloths dipped in this solution and wrapped in polyethylene clear wrap. Standing specimens are kept in a refrigerator at $4^{\circ} \mathrm{C}$ when not being dissected.

Over a three-month period the fixed horses were swabbed weekly to determine the ongoing microbial status of the specimens. Adverse effects, such as aerobic and anaerobic bacteria, yeast, or mould growth were not observed.

\section{Technique comments}

There are a wide variety of mechanical pumps in use for cadaver perfusion (Brenner 2014). Probably the most common are peristaltic pumps because of their reliability, ease of use, and longevity. The perfusion pressures used differ to some extent with species. With horses a maximum of 2 bar works well. Pressures above these limits can cause blood vessels to rupture and fixative to pool in the body cavities, especially in the abdomen. On some occasions excessively high pressures cause the fixative to be shunted away from the systemic circulation and to flow from the nasal and oral cavities.

In our institution, we use formaldehyde at a low concentration (2-3\%) in the fixation of horses. Formaldehyde is the most common biocidal substance used to embalm cadavers in veterinary and human medicine. It is an excellent preservative as it causes denaturation of proteins and inhibits microbial growth. Human exposure to formaldehyde, however, has health risks, including carcinogenesis (IARC 2006). To reduce the risks associated with formaldehyde, newly developed protocols and aerosol sampling have been implemented (Thullner et al. 2015, Waschke et al. 2019). In our studies, we are very aware of the risks of formaldehyde and have investigated fixation methods both without or with as little as possible (Janczyk et al. 2011 a, b, Klopfleisch et al. 2012). However, the adequate

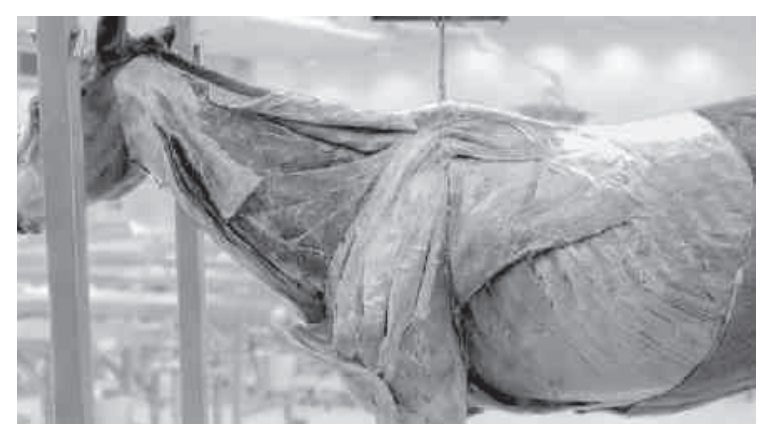

Fig. 2 Preparation of the deep layer of the extrinsic musculature of the thoracic limb: skin and subcutaneous musculature are removed and the trapezius muscle is peeled back. Skin, muscles, fasciae and fatty tissues can be separated from each other easily. Colour preservation and tissue textures are realistic. | Präparation der tiefen Schultergürtelmuskulatur: Haut und Hautmuskeln entfernt, M. trapezius weggeklappt. Haut, Muskulatur und Faszien sowie Fettgewebe lassen sich gut voneinander lösen. Die Farberhaltung, Konsistenz und damit lebensnahe Darstellung sind als sehr gut einzuschätzen. fixation of horses in a standing position requires the addition of formaldehyde to give it a suitable degree of rigidity. In our institution constituents of a 100 litres of formaldehyde-based fixative are as follows: 30 litres of $100 \%$ ethanol and 20 litres of polyethylene glycol 400. Then 8.1 litres of formaldehyde (37\%), and 41.9 litres of water for a $3 \%$ solution or 5.4 litres of formaldehyde $(37 \%)$, and 44.6 litres of water for a $2 \%$ solution are added.

Smaller species such as goats and sheep have been successfully perfused at 1 bar, whereas dogs have been perfused at 0.5 bar. In these cases the formaldehyde based fixative is used at $2 \%$.

\section{Conclusions}

The provision of horse specimens fixed in a normal standing position for whole body dissections is an enriching teaching and learning activity because it resembles normal clinical circumstances when examining these animals for medical or surgical reasons. Even though the anatomy of the limbs can be examined on disarticulated specimens, dissection and surgical training using whole bodies in the standing position is a superior method as it more closely emulates the normal axial and appendicular biomechanical forces affecting the limbs (Cake 2006, Papa and Vaccarezza 2013, Davis et al. 2014, Sheikh et al. 2015). In addition to dissection of musculoskeletal elements, studying organ systems 'in situ' is certainly the superior method to demonstrate normal topographic visceral interrelationships between organs, their ligamentous associations, vasculature and innervation (Sheikh et al. 2015). This again is important for the interpretation of images obtained by radiography or other imaging techniques as well as the planning and implementation of surgical interventions.

Depending on the needs of anatomy teaching in different countries, camelids can also be fixed as described in the present study.

\section{Conflict of interest statement}

There is no possible conflict of interest.

\section{Animal welfare statement}

This is not an experimental study using animals.

\section{Statement of informed consent}

This is not a patient based-study.

\section{References}

Brenner E. (2014) Human body preservation - old and new techniques. J. Anat. 224, 316-344

Cake M. A. (2006) Deep dissection: Motivating students beyond rote learning in veterinary anatomy. J. Vet. Med. Educ. 33, 266-271

Davis C. R., Bates A. S., Ellis H., Roberts A. M. (2014) Human anatomy: Let the students tell us how to teach. Anat. Sci. Educ. 7, 262-272 
Elarbi M. M., Ragle C. A., Fransson B. A., Farnsworth K. D. (2018) Face, construct, and concurrent validity of a simulation model for laparoscopic ovariectomy in standing horses. J. Am. Vet. Med. Assoc. 253 (1), 92-100

Hendrickson D. A. (2012) A Review of Equine Laparoscopy. Internat. Schol. Res. Network Article ID 492650, 17 pages; DOI $10.5402 / 2012 / 492650$

IARC (2006) Formaldehyde, 2-butoxyethanol and 1-tert-butoxypropan-2-ol. In: IARC Monogr. Eval. Carcinog. Risks Hum. 88, 1-478. PMID: 17366697; ISBN-13 (Print Book) 978-92-832-1288-1

Janczyk P., Weigner J., Luebke-Becker A., Kaessmeyer S., Plendl J. (201 1a) Nitrite pickling salt as an alternative to formaldehyde for embalming in veterinary anatomy - A study based on histo-and microbiological analyses. Ann. Anat. 193, $71-75$

Janczyk P., Weigner J., Luebke-Becker A., Richardson K. C., Plendl J. (2011 b) A pilot study on ethanol-polyethylene glycol-formalin fixation of farm animal cadavers. Pilotstudie zur Fixierung von Großtieren mittels Äthanol-Polyäthylenglykol-Formalin. Berl. Münch. Tierarztl. Wochenschr. 124, 225-227

Klopfleisch R., von Deetzen M., Weiss A. T., Weigner J., Weigner F., Plendl J., Gruber A. D. (2013) Weigners fixative - an alternative to formalin fixation for histology with improved preservation of nucleic acids. Vet. Pathol. 50, 191-199

Papa V., Vaccarezza M. (2013) Teaching anatomy in the XXI century: new aspects and pitfalls. Sci. World J. 2013, 310-348
Sheikh A. H., Barry D. S., Gutierrez H., Cryan J. F., O'Keeffe G. W. (2015) Cadaveric anatomy in the future of medical education: What is the surgeons view? Anat. Sci. Educ. 9, 203-208

Theoret C. L., Carmel É. N., Bernier S. (2007) Why dissection videos should not replace cadaver prosections in the gross veterinary anatomy curriculum: Results from a comparative study. J. Vet. Med. Educ. 34, 151-156

Thullner I., Stockmann R., Hohenberger L. (2015) Formaldehyd in der vorklinischen medizinischen Ausbildung (Anatomie). Fachzeitschrift Gefahrstoffe - Reinhaltung der Luft - Air Quality Control, 75 (6), 219-228. (Herausgeber: Institut für Arbeitsschutz der DGUV (IFA) and VDI/DIN-Kommission Reinhaltung der Luft.)

Tiplady C., Lloyd S., Morton J. (2011) Veterinary science student preferences for the source of dog cadavers used in anatomy teaching. Altern. Lab. Anim. 39, 461-469

Waschke J., Bergmann M., Bräuer L., Brenner E., Buchhorn A., Deutsch A., Dokter M., Egu D. T., Ergün S., Fassnacht U., Fietz D., Gundlach S., Heermann S., Hirt B., Kugelmann D., Müller-Gerbl M., Neiss W., Nimtschke U., Plendl J., Pretterklieber M., Redies C., Scaal M., Schmidt M. H. H., Schmiedl A., Schnittler H. J., Schomerus C., Sebestény T., Spittau B., Steiniger B., Tschernig T., Unverzagt A., Viebahn C., Voigt E., Weigner J., Weyers I., Winkelmann A., Winkler M., Paulsen F. (2019) Recommendations of the working group of the Anatomische Gesellschaft on reduction of formaldehyde exposure in anatomical curricula and institutes. Ann. Anat. 221, 179-185; DOI 10.1016/i.aanat.2018.10.007. 